\title{
Tuning the Single-Molecule Magnetism of Dysprosium Complexes by a Redox-Noninnocent Diborane Ligand
}

Chao Chen, ${ }^{\dagger+}$ Zhaobo Hu, ${ }^{\dagger \dagger}$ Huapeng Ruan, ${ }^{\dagger}$ Yue Zhao, ${ }^{\dagger}$ Yi-Quan Zhang,, Gengwen Tan, ${ }^{*} \&$ You Song, *† Xinping Wang*†

$\uparrow$ State Key Laboratory of Coordination Chemistry, Jiangsu Key Laboratory of Advanced Organic Materials, School of Chemistry and Chemical Engineering, Collaborative Innovation Center of Advanced Microstructures, Nanjing University, Nanjing 210023, China

\& College of Chemistry, Chemical Engineering and Materials Science, Soochow University, Suzhou 215123, China

" Jiangsu Key Laboratory for NSLSCS, School of Physical Science and Technology, Nanjing Normal University, Nanjing 210023, China

E-mail: gengwentan@nju.edu.cn; yousong@nju.edu.cn; xpwang@nju.edu.cn

$\$$ These two authors contributed equally to this work 


\section{Content}

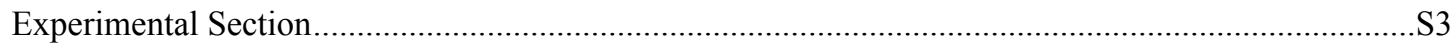

Figure S1. UV/Vis spectra of 1-4 measured in THF solutions at room temperature. ...........................S5

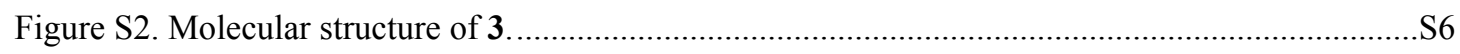

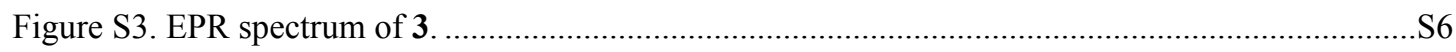

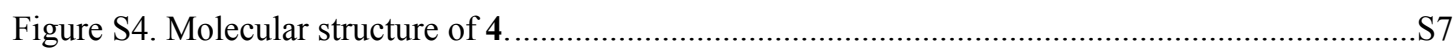

Figure S5. (a): Isothermal magnetization at different temperatures for 1. (b): Experimental $M$ vs $H / T$

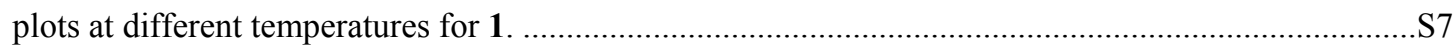

Figure S6. (a): Isothermal magnetization at different temperatures for 2. (b): Experimental $M$ vs $H / T$

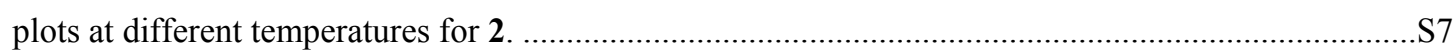

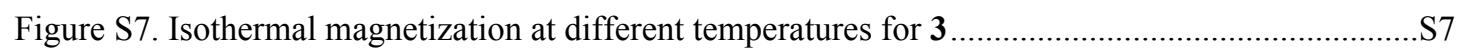

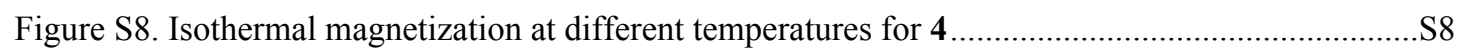

Figure S9. Isothermal field sweep measurement and the plots $\tau v S$. $H$ for complex 1.......................S8

Figure S10. Isothermal field sweep measurement and the plots $\tau v s . H$ for complex 2......................S8

Figure S11. Frequency-dependent of the in-put-phase $\left(\chi^{\prime}\right)$ under $1.0 \mathrm{kOe}$ dc-field for 1 ......................S9

Figure S12. Frequency-dependent of the out-of-phase $\left(\chi^{\prime \prime}\right)$ under $1.0 \mathrm{kOe}$ dc-field for 1 ...................S9

Figure S13. Cole-Cole curves under $1000 \mathrm{Oe}(\mathrm{d})$ of complex 1....................................................S9

Table S1. The fit parameters obtained from analyses of the ac susceptibilities of 1 under $1.0 \mathrm{kOe}$ dc

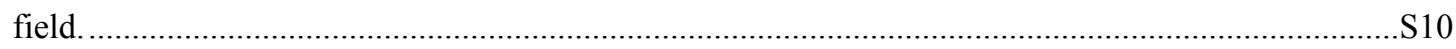

Table S2. The fit parameters obtained from analyses of the ac susceptibilities of 2 under $1.0 \mathrm{kOe}$ dc

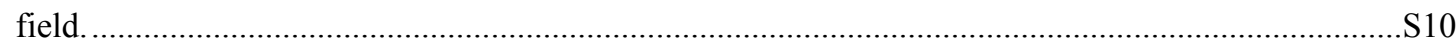

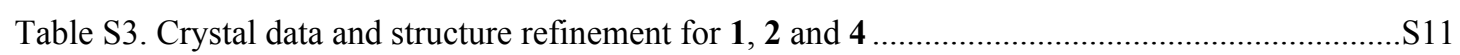

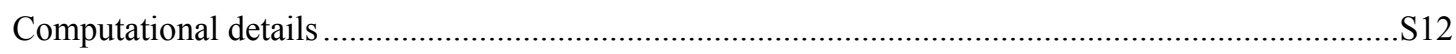

Figure S14. Calculated complete molecular structures of complexes 1 and 2 .............................S12

Table S4. Calculated energy levels $\left(\mathrm{cm}^{-1}\right), g\left(g_{\mathrm{x}}, g_{\mathrm{y}}, g_{\mathrm{z}}\right)$ tensors and predominant $m J$ values of the lowest eight Kramers doublets (KDs) of complexes $\mathbf{1}$ and $\mathbf{2}$ using CASSCF/RASSI-SO with MOLCAS 8.4.

Table S5. Wave functions with definite projection of the total moment $\mid \mathrm{mJ}>$ for the lowest two KDs of individual DyIII fragments for complexes 1 and 2 using CASSCF/RASSI with MOLCAS 8.4.S13 Figure S15. Magnetization blocking barriers in complexes $\mathbf{1}$ and $\mathbf{2}$.

Figure S16. Calculated orientations of the local main magnetic axes on Dy ${ }^{\mathrm{III}}$ ions of complexes 1 and 2 in the ground KDs.

Table S6. Exchange energies $E\left(\mathrm{~cm}^{-1}\right)$, the energy difference between each exchange doublets $\Delta t$ $\left(\mathrm{cm}^{-1}\right)$ and the main values of the $g_{\mathrm{z}}$ for the lowest two exchange doublets of $\mathbf{1}$.

Figure S17. Calculated (red solid line) and experimental data of magnetic susceptibilities of complex 1.

References S17 


\section{Experimental Section}

All experiments were carried out under a dry oxygen-free nitrogen atmosphere using standard Schlenk techniques. Solvents were dried by standard methods and freshly distilled prior to use. UV/Vis spectra were recorded on Lambda 750 spectrometer. Elemental analyses were performed on an Elementar Vario EL III instrument at Shanghai Institute of Organic Chemistry, the Chinese Academy of Sciences. The temperature-dependent magnetic data for polycrystalline samples were collected on a Quantum Design MPMP-XL7 superconducting quantum interference device (SQUID) magnetometer, while the field-dependent magnetization and alternative-current properties of complexes 1 were measured on a MPMS Squid VSM. For the single crystal X-ray structure analyses the crystals were each mounted on a glass capillary in perfluorinated oil and measured in a cold $\mathrm{N}_{2}$ flow. The data were collected on Bruker D8 CMOS detectors at $123 \mathrm{~K}$. The structures were solved by direct methods and all refined on $F^{2}$ with the SHELX-2018/3 software package. The positions of the $\mathrm{H}$ atoms were calculated and considered isotropically according to a riding model. Commercially available reagents were purchased from Aldrich, Acros or Alfa-Assar, and used as received. 5,5'-Bis-(dimesitylboranyl)-2,2'-bipyridine (bpy ${ }^{\mathrm{B}}{ }^{\mathrm{S} 1}$ and $\left[\mathrm{Cp}_{2}{ }_{2} \mathrm{Ln}\right]\left[\mathrm{BPh}_{4}\right](\mathrm{Ln}=\mathrm{Dy} \text { and } \mathrm{Gd})^{\mathrm{S} 2}$ were synthesized according to the reported procedures.

Synthesis of 1: bpy $^{\mathrm{B}}(130.5 \mathrm{mg}, 0.2 \mathrm{mmol})$ and $\left[\mathrm{Cp}^{*}{ }_{2} \mathrm{Dy}\right]\left[\mathrm{BPh}_{4}\right](150.1 \mathrm{mg}, 0.2 \mathrm{mmol})$ were placed in a Schlenk flask $(50 \mathrm{~mL})$, and THF $(20 \mathrm{~mL})$ was added via cannula under a nitrogen atmosphere. The mixture was stirred at room temperature for $4 \mathrm{~h}$ before addition of $\mathrm{K}$ ( $7.8 \mathrm{mg}, 0.2$ $\mathrm{mmol}$ ), then the mixture was stirred for another $12 \mathrm{~h}$. All the volatiles were removed under vacuum, and the dark yellow residue was extracted with $n$-hexane $(30 \mathrm{~mL})$ and filtered. The filtrate was concentrated to ca. $15 \mathrm{~mL}$ and left at $4{ }^{\circ} \mathrm{C}$ for $24 \mathrm{~h}$ to afford dark yellow crystals of $\mathbf{1}$. Yield: $63 \mathrm{mg}, 29 \%$. Elemental analysis for $\mathrm{C}_{66} \mathrm{H}_{80} \mathrm{DyN}_{2} \mathrm{~B}_{2}$ (\%): Cacld: C 73.03, H 7.43, N 2.58; Found: C 73.33, H 7.19, N 2.39.

Synthesis of 2: $\mathrm{bpy}^{\mathrm{B}}(130.5 \mathrm{mg}, 0.2 \mathrm{mmol})$ and $\left[\mathrm{Cp}^{*}{ }_{2} \mathrm{Dy}\right]\left[\mathrm{BPh}_{4}\right](150.1 \mathrm{mg}, 0.2 \mathrm{mmol})$ were placed in a Schlenk flask $(50 \mathrm{~mL})$, and THF $(20 \mathrm{~mL})$ was added via cannula under a nitrogen atmosphere. The mixture was stirred at room temperature for $4 \mathrm{~h}$ before addition of $\mathrm{K}$ (16.4 mg, $0.42 \mathrm{mmol}$ ) and 222-cryptand (75.3 mg, $0.2 \mathrm{mmol})$. Then the mixture was stirred for another $12 \mathrm{~h}$. All the volatiles were removed under vacuum, and the dark blue residue was extracted with 
toluene $(30 \mathrm{~mL})$ and filtered. All the volatiles in the filtrate were removed again. The residue was redissolved in THF $(10 \mathrm{~mL})$ and filtered. The filtrate was concentrated and layered with $n$-hexane $(5 \mathrm{~mL})$. The solution was left at $-20^{\circ} \mathrm{C}$ for $24 \mathrm{~h}$ to afford blue crystals of 2 . Yield: $124 \mathrm{mg}, 41 \%$. Elemental analysis for $\mathrm{C}_{84} \mathrm{H}_{116}$ DyKN $_{4} \mathrm{O}_{6} \mathrm{~B}_{2}$ (\%): Cacld: C 67.21, H 7.79, N 3.73; Found: C 66.52, H 7.62, N 3.52.

Synthesis of 3: $\mathrm{bpy}^{\mathrm{B}}(130.5 \mathrm{mg}, 0.2 \mathrm{mmol})$ and $\left[\mathrm{Cp}^{*}{ }_{2} \mathrm{Gd}\right]\left[\mathrm{BPh}_{4}\right](149.4 \mathrm{mg}, 0.2 \mathrm{mmol})$ were placed in a Schlenk flask $(50 \mathrm{~mL})$, and THF $(20 \mathrm{~mL})$ was added via cannula under a nitrogen atmosphere. The mixture was stirred at room temperature for $4 \mathrm{~h}$ before addition of $\mathrm{K}$ ( $7.8 \mathrm{mg}, 0.2$ $\mathrm{mmol}$ ), then the mixture was stirred for another $12 \mathrm{~h}$. All the volatiles were removed under vacuum, and the dark yellow residue was extracted with $n$-hexane $(30 \mathrm{~mL})$ and filtered. The filtrate was concentrated to ca. $15 \mathrm{~mL}$ and left at $4{ }^{\circ} \mathrm{C}$ for $24 \mathrm{~h}$ to afford dark yellow crystals of 3 . Yield: $45 \mathrm{mg}, 21 \%$. Elemental analysis for $\mathrm{C}_{66} \mathrm{H}_{80} \mathrm{GdN}_{2} \mathrm{~B}_{2}$ (\%): Cacld: C 73.38, H 7.46, N 2.59; Found: C 73.45, H 7.68, N 2.48.

Synthesis of 4: bpy ${ }^{\mathrm{B}}(130.5 \mathrm{mg}, 0.2 \mathrm{mmol})$ and $\left[\mathrm{Cp}^{*}{ }_{2} \mathrm{Gd}\right]\left[\mathrm{BPh}_{4}\right](149.4 \mathrm{mg}, 0.2 \mathrm{mmol})$ were placed in a Schlenk flask $(50 \mathrm{~mL})$, and THF $(20 \mathrm{~mL})$ was added via cannula under a nitrogen atmosphere. The mixture was stirred at room temperature for $4 \mathrm{~h}$ before addition of $\mathrm{K}$ (16.4 mg, $0.42 \mathrm{mmol}$ ) and 222-cryptand $(75.3 \mathrm{mg}, 0.2 \mathrm{mmol})$. The mixture was stirred for another $12 \mathrm{~h}$. All the volatiles were removed under vacuum, and the dark blue residue was extracted with toluene $(30 \mathrm{~mL})$ and filtered. All the volatiles in the filtrate were removed again, and the residue was extracted with THF $(10 \mathrm{~mL})$. The obtained blue solution was layered with $\mathrm{n}$-hexane $(5 \mathrm{~mL})$ and left at $-20{ }^{\circ} \mathrm{C}$ for $24 \mathrm{~h}$ to afford blue crystals of 4 . Yield: $124 \mathrm{mg}, 41 \%$. Elemental analysis for $\mathrm{C}_{84} \mathrm{H}_{116} \mathrm{GdKN}_{4} \mathrm{O}_{6} \mathrm{~B}_{2}(\%)$ : Cacld: C 67.45, H 7.82, N 3.75; Found: C 67.52, H 7.67, N 3.41. 


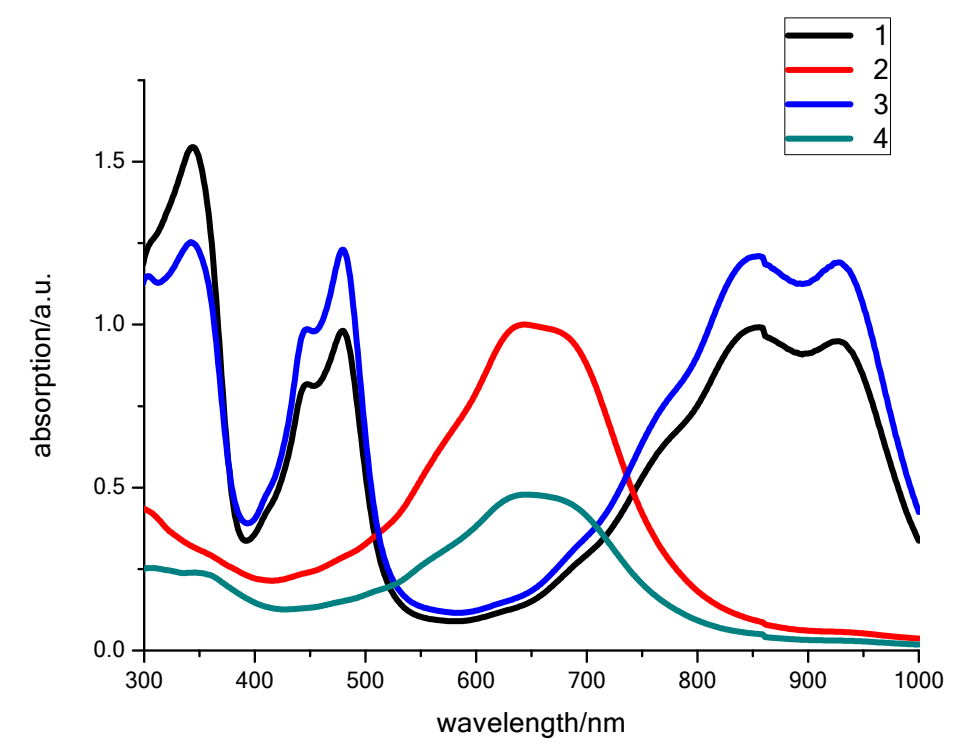

Figure S1. UV/Vis spectra of 1-4 measured in THF solutions at room temperature.

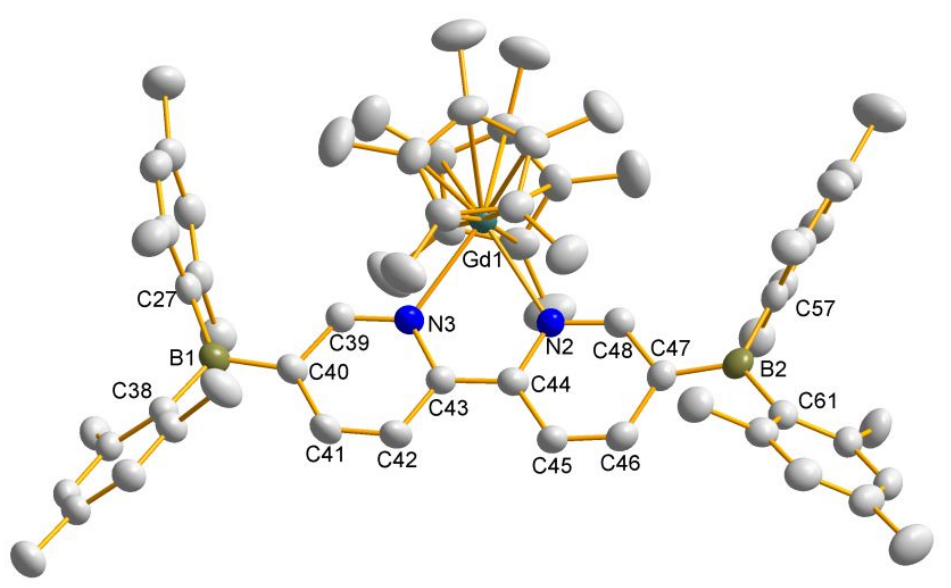

Figure S2. Molecular structure of 3. Selected bond lengths $(\AA)$ : B1-C40 1.510(3), B1-C38 1.600(4), B1-C27 1.605(4), B2-C47 1.503(3), B2-C57 1.596(4), B2-C61 1.601(3), C43-C44 1.388(3), C43-N3 1.407(3), C44-N2 1.403(3), C48-N2 1.324(3), C39-N3 1.323(3), Gd1-N3 2.3924(19), Gd1-N2 2.3922(18); C40-B1-C38 119.2(2), C40-B1-C27 116.6(2), C38-B1-C27 124.1(2), C47-B2-C57 120.0(2), C47-B2-C61 121.0(2), C57-B2-C61 119.0(2). 


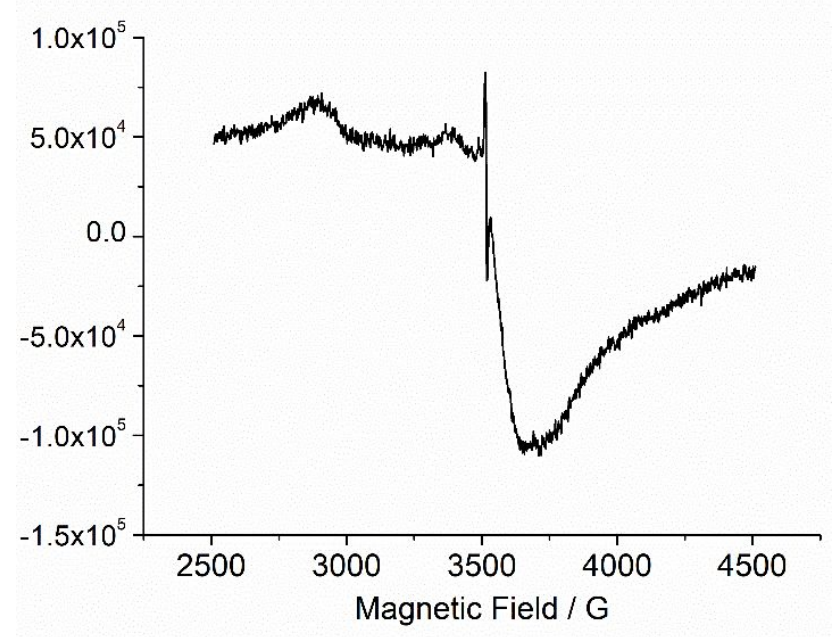

Figure S3. EPR spectrum of $\mathbf{3}$ in THF at room temperature.

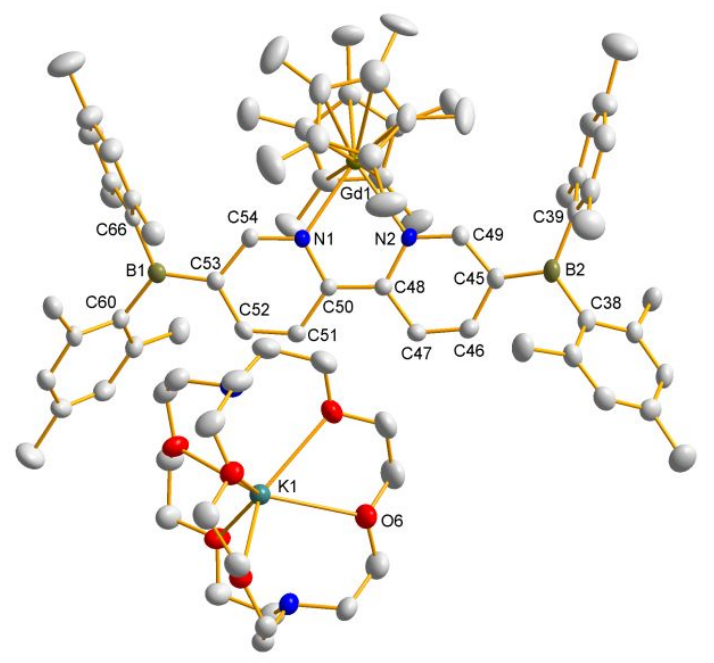

Figure S4. Molecular structure of 4. Selected bond lengths ( $\AA$ ): B1-C53 1.511(6), B2-C45 1.504(6), C45-C49 1.410(6), C45-C46 1.459(6), C46-C47 1.353(6), C47-C48 1.440(5), C48C50 1.394(5), C48-N2 1.417(5), C49-N2 1.320(5), C50-N1 1.411(5), C50-C51 1.443(5), C51C52 1.356(5), C52-C53 1.454(5), C53-C54 1.419(5), C54-N1 1.333(5), Gd1-N2 2.395(3), Gd1N1 2.395(3). 

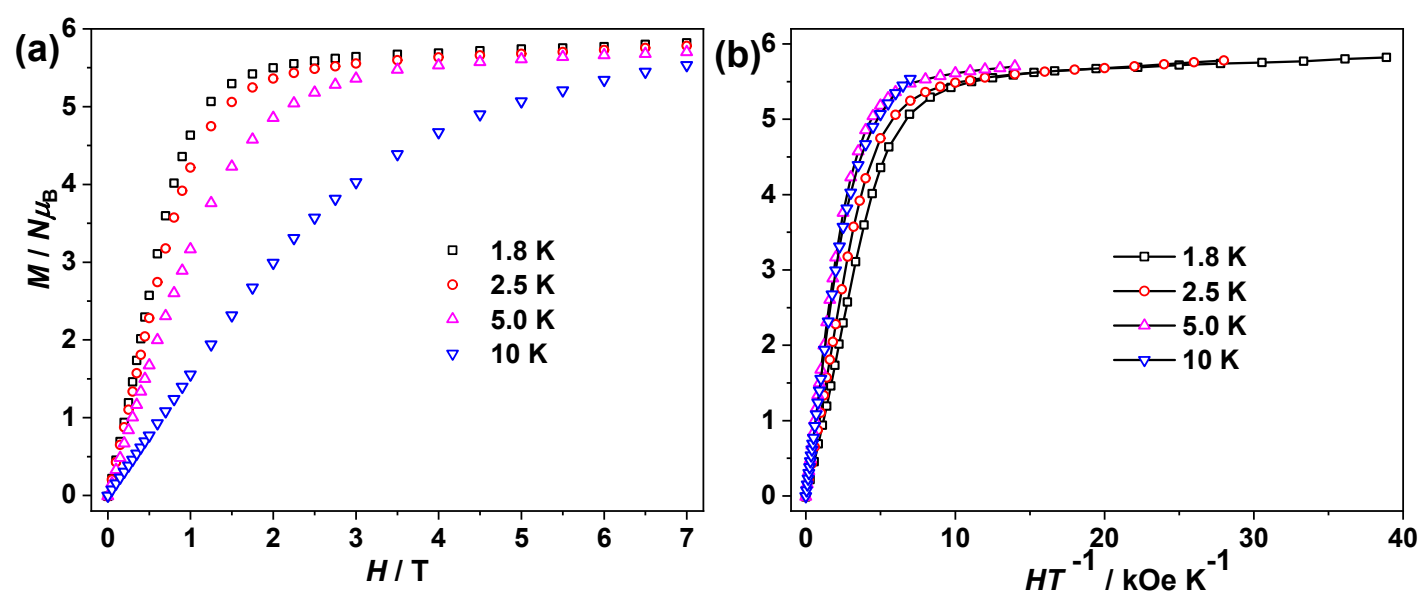

Figure S5. (a): Isothermal magnetization at different temperatures for 1. (b): Experimental $M$ vs $H / T$ plots at different temperatures for $\mathbf{1}$.
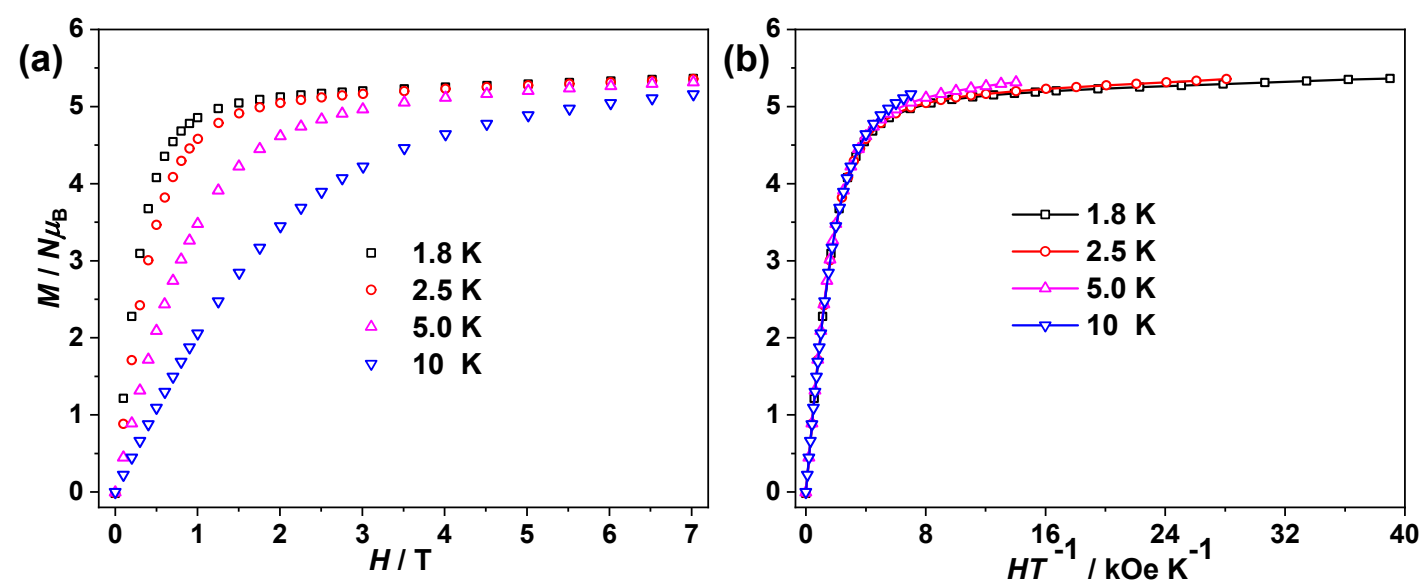

Figure S6. (a): Isothermal magnetization at different temperatures for 2. (b): Experimental $M$ vs $H / T$ plots at different temperatures for $\mathbf{2}$.

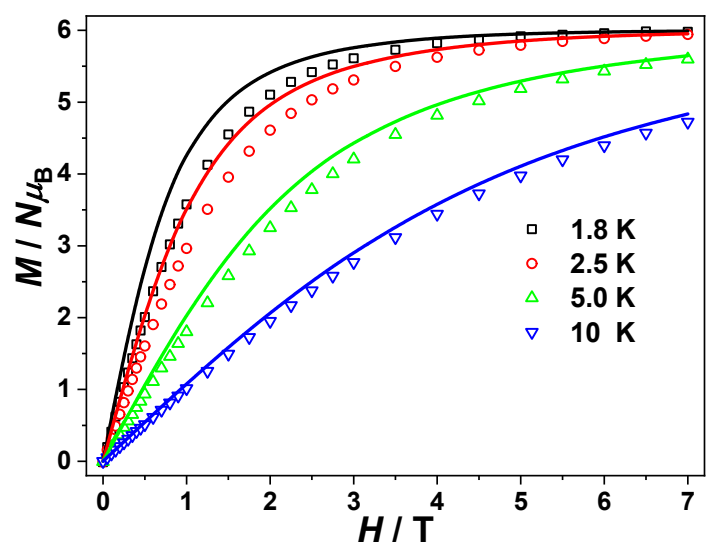

Figure S7. Isothermal magnetization at different temperatures for 3. The solid lines represent the best fitted result by $P H I$. 


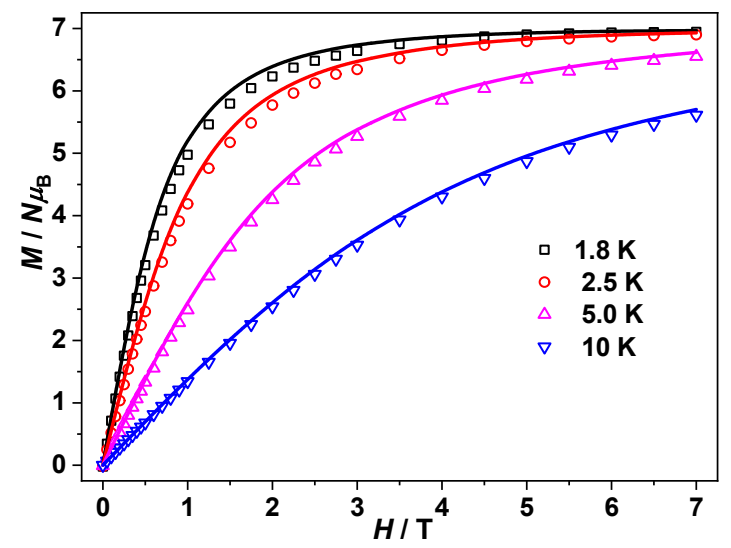

Figure S8. Isothermal magnetization at different temperatures for 4 . The solid lines represent the best fitted result by $P H I$.
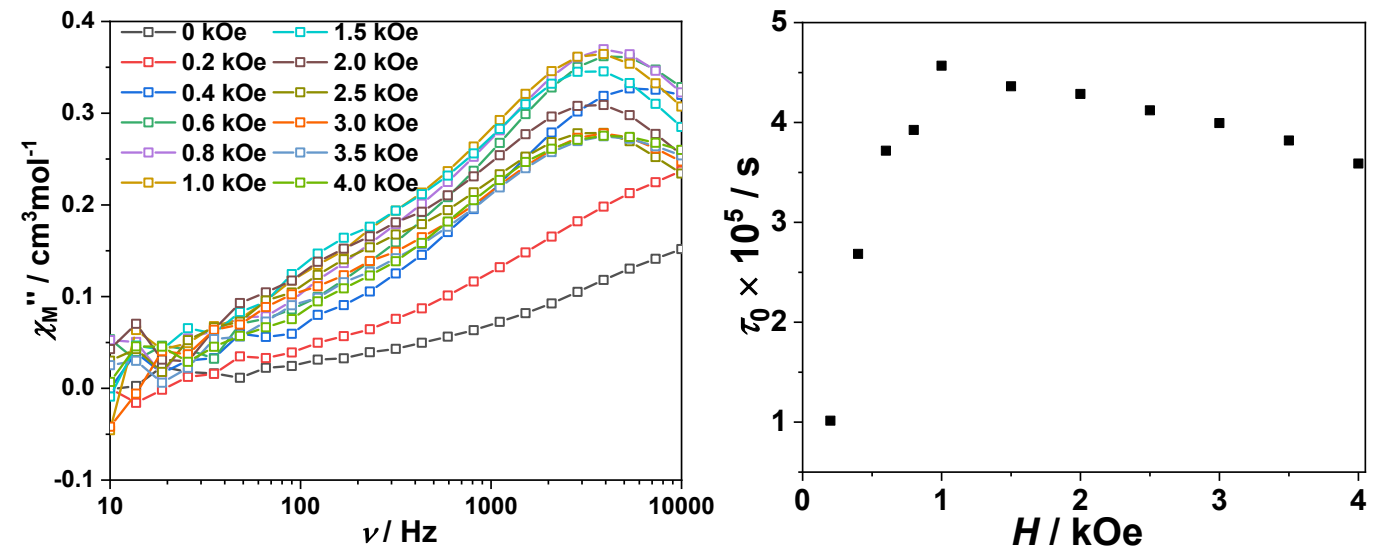

Figure S9. Isothermal field sweep measurement performed on polycrystalline sample of complex 1 (left). The plots $\tau v s . H$ for complex 1 (right).
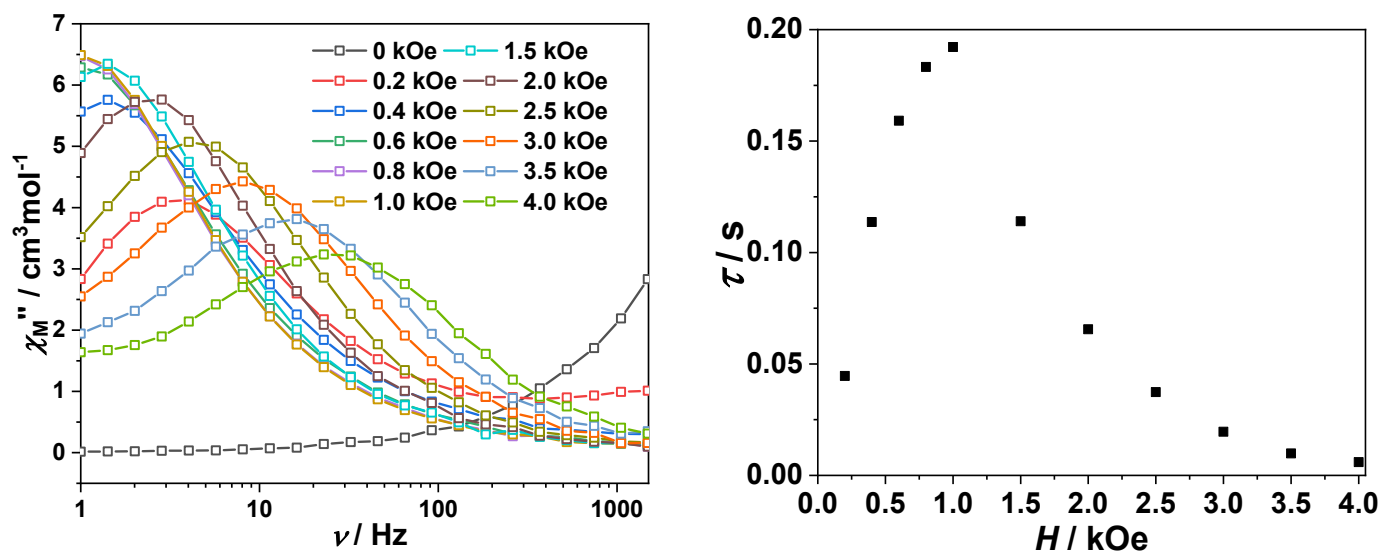

Figure S10. Isothermal field sweep measurement performed on polycrystalline sample of complex 2 (left). The plots $\tau v s . H$ for complex 2 (right). 


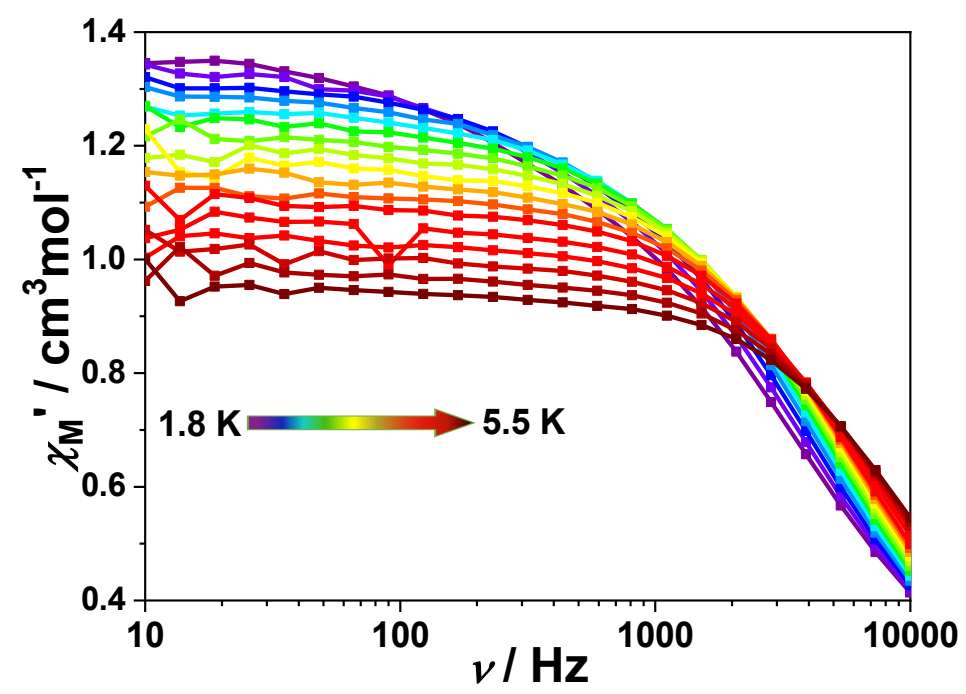

Figure S11. Frequency-dependent of the in-put-phase $\left(\chi^{\prime}\right)$ under $1.0 \mathrm{kOe}$ dc-field for $\mathbf{1 .}$

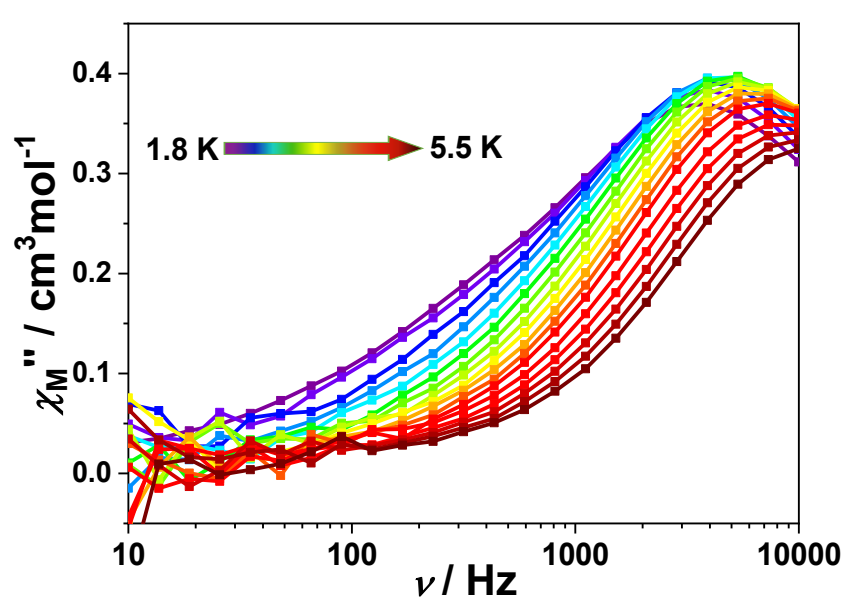

Figure S12. Frequency-dependent of the out-of-phase $\left(\chi^{\prime \prime}\right)$ under $1.0 \mathrm{kOe}$ dc-field for $\mathbf{1}$.

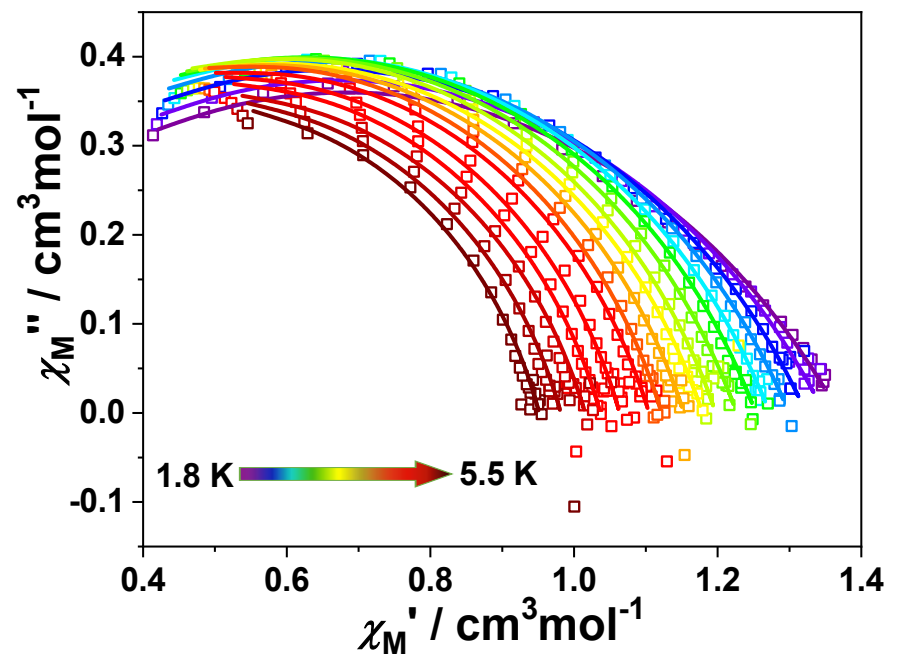

Figure S13. Cole-Cole curves under 1000 Oe (d) of complex 1. 
Table S1. The fit parameters obtained from analyses of the ac susceptibilities of $\mathbf{1}$ under $1.0 \mathrm{kOe}$ dc field.

\begin{tabular}{|c|c|c|c|c|c|}
\hline$T / K$ & $\chi_{\mathrm{T}} / \mathrm{cm}^{3} \mathrm{~mol}^{-1}$ & $\chi_{\mathrm{S}} / \mathrm{cm}^{3} \mathrm{~mol}^{-1}$ & $\ln (\tau / \mathrm{s})$ & $a$ & $R^{2}$ \\
\hline 1.8 & 1.36839 & $7.39584 \mathrm{E}-16$ & -10.01643 & 0.38148 & 0.00255 \\
\hline 2 & 1.34846 & $1.09392 \mathrm{E}-15$ & -10.12632 & 0.35374 & 0.00288 \\
\hline 2.2 & 1.32332 & $1.61389 \mathrm{E}-15$ & -10.2351 & 0.32618 & 0.00554 \\
\hline 2.4 & 1.29925 & $2.64044 \mathrm{E}-15$ & -10.32898 & 0.30275 & 0.00203 \\
\hline 2.6 & 1.27239 & $3.88167 \mathrm{E}-15$ & -10.4169 & 0.28428 & 0.00221 \\
\hline 2.8 & 1.25293 & $5.67862 \mathrm{E}-15$ & -10.48835 & 0.27415 & 0.00294 \\
\hline 3 & 1.22641 & $8.10268 \mathrm{E}-15$ & -10.56434 & 0.26267 & 0.004 \\
\hline 3.2 & 1.19729 & $1.14915 \mathrm{E}-14$ & -10.63865 & 0.24994 & 0.00586 \\
\hline 3.4 & 1.17875 & $1.72333 \mathrm{E}-14$ & -10.69834 & 0.24859 & 0.01281 \\
\hline 3.6 & 1.15284 & $2.60843 \mathrm{E}-14$ & -10.76319 & 0.23775 & 0.00552 \\
\hline 3.8 & 1.12183 & $3.99677 \mathrm{E}-14$ & -10.83172 & 0.22454 & 0.00431 \\
\hline 4 & 1.1044 & $5.84133 \mathrm{E}-14$ & -10.88525 & 0.22612 & 0.00855 \\
\hline 4.3 & 1.0635 & $9.1035 \mathrm{E}-14$ & -10.99256 & 0.21427 & 0.00841 \\
\hline 4.6 & 1.03668 & $1.34915 \mathrm{E}-13$ & -11.07312 & 0.21185 & 0.00603 \\
\hline 4.9 & 1.01537 & $1.84932 \mathrm{E}-13$ & -11.14989 & 0.21995 & 0.00564 \\
\hline 5.2 & 0.98162 & $2.85627 \mathrm{E}-13$ & -11.23495 & 0.21011 & 0.00875 \\
\hline 5.5 & 0.95142 & $4.35139 \mathrm{E}-13$ & -11.31719 & 0.20106 & 0.01659 \\
\hline
\end{tabular}

Table S2. The fit parameters obtained from analyses of the ac susceptibilities of $\mathbf{2}$ under $1.0 \mathrm{kOe}$ dc field.

\begin{tabular}{llllll}
\hline$T / K$ & $\chi_{\mathrm{T}} / \mathrm{cm}^{3} \mathrm{~mol}^{-1}$ & $\chi_{\mathrm{S}} / \mathrm{cm}^{3} \mathrm{~mol}^{-1}$ & $\ln (\tau / \mathrm{s})$ & $a$ & $R^{2}$ \\
\hline 3 & 20.1215 & 0.36104 & -1.73738 & 0.23072 & 0.17914 \\
3.5 & 16.0287 & 0.34281 & -2.73932 & 0.18026 & 0.26063 \\
4 & 13.6237 & 0.35989 & -3.5564 & 0.14378 & 0.29506 \\
4.5 & 11.9306 & 0.37583 & -4.26262 & 0.11635 & 0.23631 \\
5 & 10.7162 & 0.33655 & -4.88938 & 0.10268 & 0.16782 \\
5.5 & 9.7246 & 0.35224 & -5.45612 & 0.08804 & 0.11393 \\
6 & 8.92177 & 0.33119 & -5.97394 & 0.07674 & 0.05912 \\
6.5 & 8.24489 & 0.30321 & -6.45979 & 0.07072 & 0.05504 \\
7 & 7.66445 & 0.29431 & -6.91143 & 0.06548 & 0.03032 \\
7.5 & 7.16547 & 0.28731 & -7.33602 & 0.05932 & 0.02974 \\
8 & 6.72991 & 0.26571 & -7.74246 & 0.05838 & 0.02544 \\
8.5 & 6.34358 & 0.27294 & -8.12252 & 0.05985 & 0.0172 \\
9 & 5.99635 & 0.26348 & -8.47232 & 0.05978 & 0.0155 \\
9.5 & 5.68755 & 0.30175 & -8.82622 & 0.04999 & 0.02043 \\
10 & 5.41181 & 0.44329 & -9.12614 & 0.04149 & 0.02351 \\
10.5 & 5.15821 & 0.24663 & -9.50677 & 0.06242 & 0.0118 \\
\hline
\end{tabular}


Table S3. Crystal data and structure refinement for 1-4

\begin{tabular}{|c|c|c|c|c|}
\hline & 1 & 2 & 3 & 4 \\
\hline formula & $\mathrm{C}_{72} \mathrm{H}_{80} \mathrm{~B}_{2} \mathrm{DyN}_{2}$ & $\begin{array}{c}\mathrm{C}_{84} \mathrm{H}_{116} \mathrm{~B}_{2} \mathrm{DyK} \\
\mathrm{N}_{4} \mathrm{O}_{6}\end{array}$ & $\mathrm{C}_{66} \mathrm{H}_{80} \mathrm{~B}_{2} \mathrm{GdN}_{2}$ & $\begin{array}{c}\mathrm{C}_{84} \mathrm{H}_{116} \mathrm{~B}_{2} \mathrm{GdKN}_{4} \\
\mathrm{O}_{6}\end{array}$ \\
\hline Formula weight & 1157.50 & 1501.02 & 1080.19 & 1495.77 \\
\hline Crystal system & Triclinic & Triclinic & Triclinic & Monoclinic \\
\hline Space group & $P-1$ & $P-1$ & $P-1$ & $P 2(1) / c$ \\
\hline$a / \AA ̊$ & $11.4377(6)$ & $12.0935(7)$ & $12.3508(4)$ & $13.678(3)$ \\
\hline$b / \AA$ & $15.2139(7)$ & $16.0916(8)$ & $18.5315(6)$ & $15.971(3)$ \\
\hline$c / \AA$ & 19.3711(10) & $24.5378(13)$ & $19.7315(6)$ & $41.015(8)$ \\
\hline$\alpha / \operatorname{deg}$ & $71.822(2)$ & $85.278(2)$ & $116.3010(10)$ & $90.00(3)$ \\
\hline$\beta / \operatorname{deg}$ & $81.019(2)$ & $79.605(2)$ & $103.2260(10)$ & $95.93(3)$ \\
\hline$\gamma / \operatorname{deg}$ & $80.611(2)$ & $73.020(2)$ & $96.8280(10)$ & $90.00(3)$ \\
\hline$V / \AA$ & $3139.7(3)$ & $4489.8(4)$ & $3813.6(2)$ & $8912(3)$ \\
\hline Z & 2 & 2 & 2 & 4 \\
\hline$\rho_{\text {calcd }} / \mathrm{g} \cdot \mathrm{cm}^{-3}$ & 1.224 & 1.110 & 0.941 & 1.115 \\
\hline cyrstal size $/ \mathrm{mm}^{3}$ & $0.18 * 0.08 * 0.06$ & $\begin{array}{c}0.170 * 0.150 * 0 \\
110\end{array}$ & $0.12 * 0.11 * 0.08$ & $0.18 * 0.15 * 0.11$ \\
\hline \multirow[t]{2}{*}{$\theta$ range/deg } & 2.229 to 25.109 & 3.006 to 53.310 & 2.139 to 25.010 & 2.383 to 26.995 \\
\hline & $-13<=\mathrm{h}<=13$ & $-14<=\mathrm{h}<=14$ & $-14<=\mathrm{h}<=12$ & $-16<=\mathrm{h}<=16$ \\
\hline \multirow[t]{2}{*}{ index ranges } & $-18<=\mathrm{k}<=18$ & $19<=\mathrm{k}<=19$ & $-21<=\mathrm{k}<=22$ & $-19<=\mathrm{k}<=18$ \\
\hline & $-23<=1<=17$ & $-29<=1<=28$ & $-23<=1<=22$ & $-48<=1<=40$ \\
\hline collected data & 22806 & 43741 & 12463 & 63239 \\
\hline unique data & 11024 & 15349 & 13249 & 15686 \\
\hline $\begin{array}{c}\text { completeness to } \\
\theta\end{array}$ & $99.6 \%$ & $96.6 \%$ & $98.5 \%$ & $99.9 \%$ \\
\hline $\begin{array}{c}\text { data/restraints/pa } \\
\text { rameters }\end{array}$ & $11024 / 0 / 662$ & $15349 / 0 / 905$ & $13249 / 0 / 662$ & $15686 / 984 / 951$ \\
\hline GOF on $F^{2}$ & 1.008 & 1.023 & 1.040 & 0.939 \\
\hline final $R$ indices & $\mathrm{R} 1=0.0435$ & $\mathrm{R} 1=0.0570$ & $\mathrm{R} 1=0.0282$ & $\mathrm{R} 1=0.0426$ \\
\hline$[I>2 \sigma(I)]$ & $\mathrm{wR} 2=0.0989$ & $\mathrm{wR} 2=0.1522$ & $\mathrm{wR} 2=0.0689$ & $\mathrm{wR} 2=0.1124$ \\
\hline $\begin{array}{c}\text { largest diff } \\
\text { peak/hole }\left(\mathrm{e} \cdot \AA^{-3}\right)\end{array}$ & $1.103 /-0.617$ & $0.778 /-1.015$ & $0.94 /-0.63$ & $0.561 /-0.848$ \\
\hline
\end{tabular}




\section{Computational details}

Complete-active-space self-consistent field (CASSCF) calculations for $\mathbf{1}$ and $\mathbf{2}$ (see Figure S1 for the complete molecular structures) on the basis of single-crystal X-ray determined geometries have been carried out with MOLCAS 8.4 program package. ${ }^{\mathrm{S} 3}$

The basis sets for all atoms are atomic natural orbitals from the MOLCAS ANO-RCC library: ANO-RCC-VTZP for DyIII ion; VTZ for close O; VDZ for distant atoms. The calculations employed the second order Douglas-Kroll-Hess Hamiltonian, where scalar relativistic contractions were taken into account in the basis set and the spin-orbit couplings were handled separately in the restricted active space state interaction (RASSI-SO) procedure. For both complexes, active electrons in 7 active spaces include all $f$ electrons $(\operatorname{CAS}(9$ in 7$))$ in the CASSCF calculation. To exclude all the doubts, we calculated all the roots in the active space. We have mixed the maximum number of spin-free state which was possible with our hardware (all from 21 sextets, 128 from 224 quadruplets, 130 from 490 doublets). SINGLE_ANISO ${ }^{\mathrm{S}}$ program was used to obtain energy levels, $\boldsymbol{g}$ tensors, $m_{J}$ values, magnetic axes, et al., based on the above CASSCF/RASSI-SO calculations.

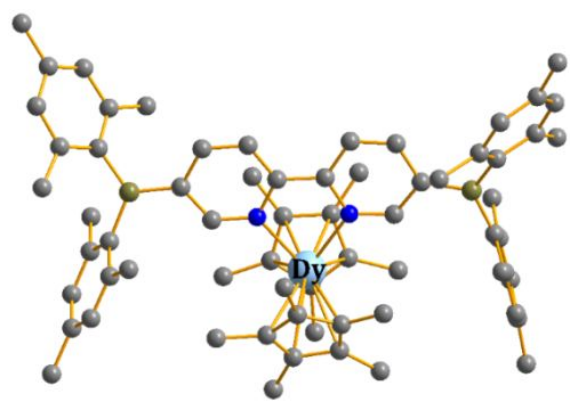

1

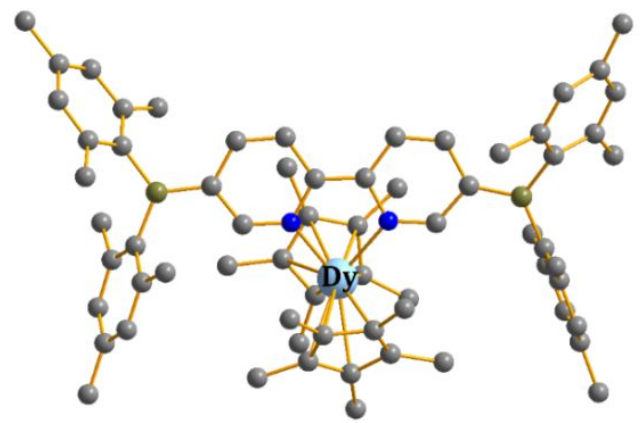

2

Figure S14. Calculated complete molecular structures of complexes $\mathbf{1}$ and $\mathbf{2} ; \mathrm{H}$ atoms are omitted. 
Table S4. Calculated energy levels $\left(\mathrm{cm}^{-1}\right), g\left(g_{\mathrm{x}}, g_{\mathrm{y}}, g_{\mathrm{z}}\right)$ tensors and predominant $\mathrm{mJ}$ values of the lowest eight Kramers doublets (KDs) of complexes 1 and $\mathbf{2}$ using CASSCF/RASSI-SO with MOLCAS 8.4.

\begin{tabular}{|c|c|c|c|c|c|c|}
\hline \multirow{2}{*}{$\begin{array}{c}\mathrm{KD} \\
\mathrm{s}\end{array}$} & \multicolumn{3}{|c|}{1} & \multicolumn{3}{|c|}{2} \\
\hline & $E$ & $g$ & $m_{J}$ & $E$ & $g$ & $m_{J}$ \\
\hline 1 & 0.0 & $\begin{array}{c}0.191 \\
0.595 \\
18.636\end{array}$ & $\pm 15 / 2$ & 0.0 & $\begin{array}{c}0.286 \\
1.195 \\
17.750\end{array}$ & $\pm 15 / 2$ \\
\hline 2 & 77.8 & $\begin{array}{c}1.326 \\
1.660 \\
16.974\end{array}$ & $\pm 9 / 2$ & 42.4 & $\begin{array}{c}0.152 \\
0.804 \\
16.440\end{array}$ & $\pm 11 / 2$ \\
\hline 3 & 136.5 & $\begin{array}{c}0.890 \\
2.384 \\
13.058\end{array}$ & $\pm 13 / 2$ & 123.7 & $\begin{array}{c}0.114 \\
1.372 \\
14.083\end{array}$ & $\pm 13 / 2$ \\
\hline 4 & 237.5 & $\begin{array}{l}5.814 \\
6.319 \\
9.363\end{array}$ & $\pm 11 / 2$ & 201.4 & $\begin{array}{c}3.144 \\
4.698 \\
11.411 \\
\end{array}$ & $\pm 9 / 2$ \\
\hline 5 & 285.4 & $\begin{array}{c}1.147 \\
1.280 \\
11.643\end{array}$ & $\pm 7 / 2$ & 247.9 & $\begin{array}{c}3.382 \\
5.523 \\
10.438 \\
\end{array}$ & $\pm 7 / 2$ \\
\hline 6 & 351.7 & $\begin{array}{c}0.121 \\
0.456 \\
14.298 \\
\end{array}$ & $\pm 5 / 2$ & 310.9 & $\begin{array}{c}0.241 \\
0.763 \\
14.037\end{array}$ & $\pm 3 / 2$ \\
\hline 7 & 462.1 & $\begin{array}{c}0.127 \\
0.184 \\
17.004\end{array}$ & $\pm 3 / 2$ & 418.2 & $\begin{array}{c}0.170 \\
0.263 \\
16.778\end{array}$ & $\pm 5 / 2$ \\
\hline 8 & 764.0 & $\begin{array}{c}0.004 \\
0.007 \\
19.777\end{array}$ & $\pm 1 / 2$ & 708.6 & $\begin{array}{c}0.007 \\
0.012 \\
19.725\end{array}$ & $\pm 1 / 2$ \\
\hline
\end{tabular}

Table S5. Wave functions with definite projection of the total moment $\mid \mathrm{mJ}>$ for the lowest two KDs of individual DyIII fragments for complexes $\mathbf{1}$ and $\mathbf{2}$ using CASSCF/RASSI with MOLCAS 8.4 .

\begin{tabular}{|c|c|c|}
\hline & $E$ & wave functions \\
\hline \multirow{3}{*}{1} & 0.0 & $81.4 \%| \pm 15 / 2>+16.1 \%| \pm 11 / 2>$ \\
\cline { 2 - 3 } & 77.8 & $\begin{array}{c}30.7 \%| \pm 1 / 2>+24.8 \%| \pm 3 / 2>+18 \%| \pm 5 / 2>+8.9 \%| \pm 9 / 2>+8 \%| \pm 13 / 2>+7.2 \%| \\
\pm 7 / 2>\end{array}$ \\
\hline \multirow{3}{*}{2} & 0.0 & $75.8 \%| \pm 15 / 2>+14 \%| \pm 11 / 2>$ \\
\cline { 2 - 3 } & 42.4 & $\begin{array}{c}25.9 \%| \pm 9 / 2>+21.7 \%| \pm 5 / 2>+12.3 \%| \pm 3 / 2>+12.2 \%| \pm 7 / 2>+10.7 \% \mid \pm 1 / 2>+8 \\
.7 \% \mid \pm 13 / 2>\end{array}$ \\
\hline
\end{tabular}




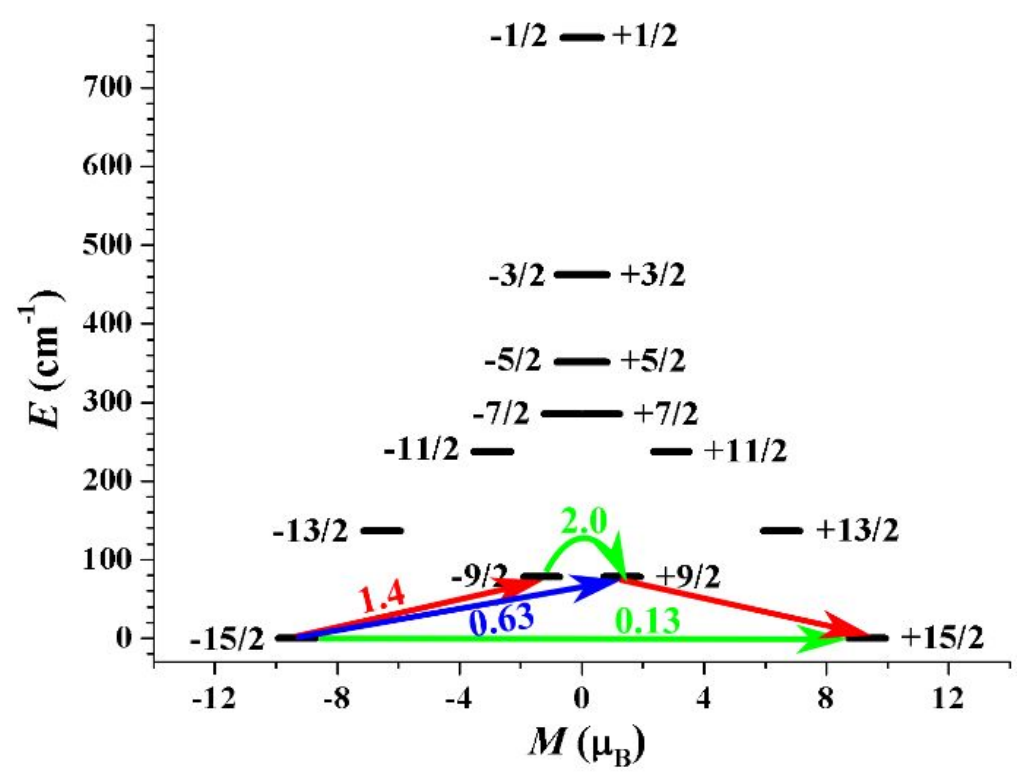

1

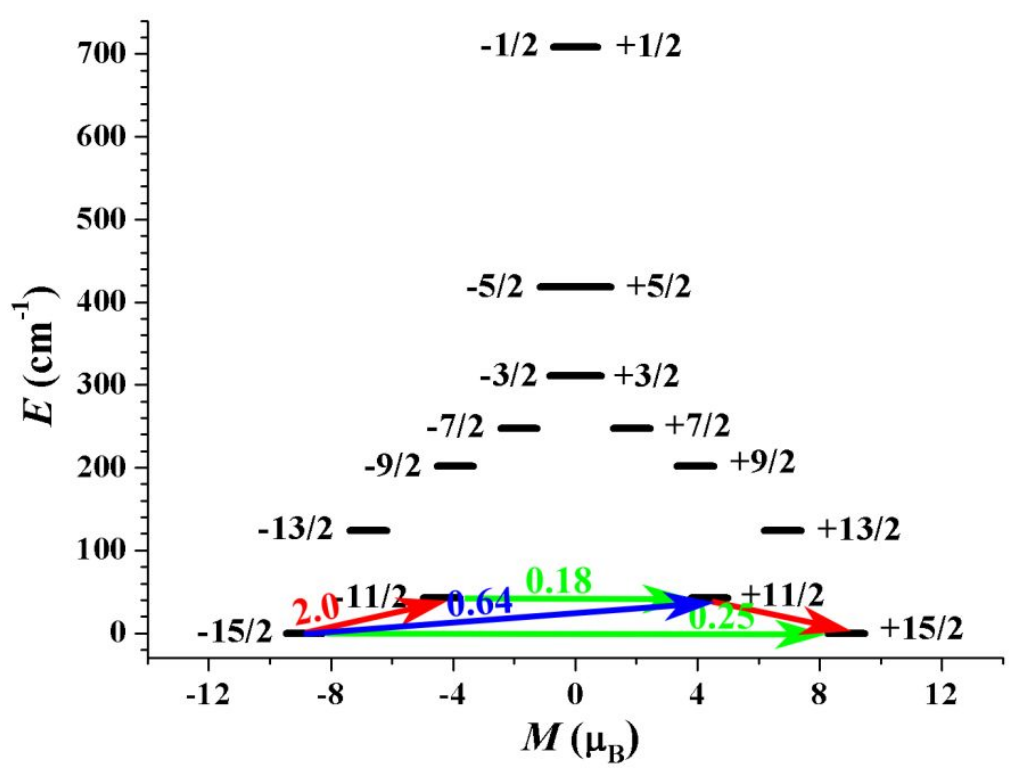

2

Figure S15. Magnetization blocking barriers in complexes 1 and 2. The thick black lines represent the KDs as a function of their magnetic moments along the magnetic axis. The green lines correspond to diagonal quantum tunneling of magnetization (QTM); the blue lines represent Orbach relaxation process. The path shown by the red arrows represents the most possibly path for magnetic relaxation in the corresponding compounds. The numbers at each arrow stand for the mean absolute value of the corresponding matrix element of transition magnetic moment. 


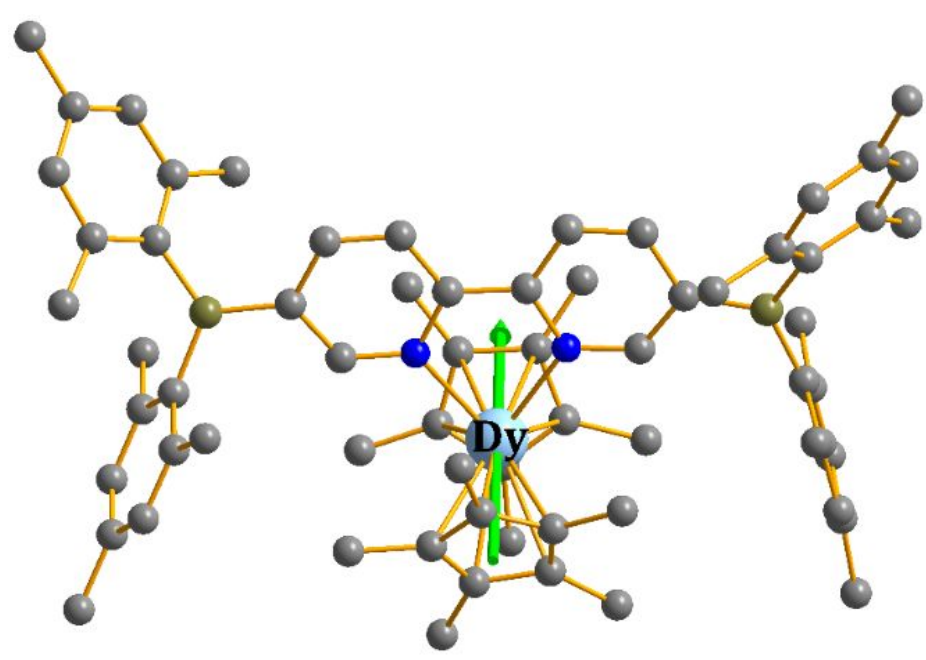

1

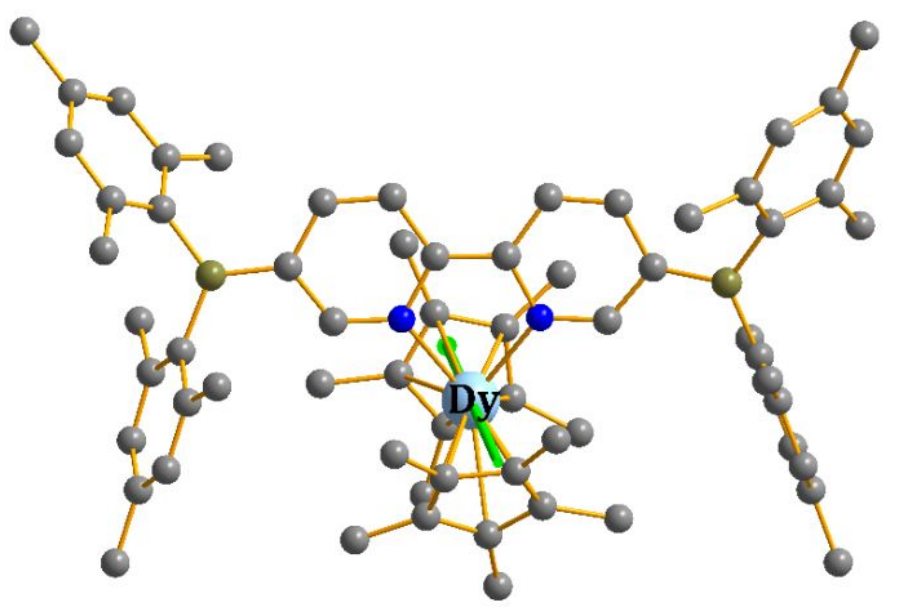

2

Figure S16. Calculated orientations of the local main magnetic axes on Dy ${ }^{\mathrm{III}}$ ions of complexes 1 and $\mathbf{2}$ in the ground KDs.

To fit the intermolecular interaction for $\mathbf{1}$, we took two steps to obtain them. Firstly, we calculated individual Dy ${ }^{\mathrm{III}}$ fragment using CASSCF/RASSI to obtain the corresponding magnetic properties. Then, the exchange interaction between the magnetic center and the radical is considered within the Lines model. ${ }^{\mathrm{S} 5}$ The average $g$ value of the radical for each complex was considered as 2.0 during the fitting. The Lines model is effective and has been successfully used widely in the research field of $f$-element single-molecule magnets. ${ }^{\mathrm{S} 6}$

For $\mathbf{1}$, there is only one type of $J$.

The exchange Ising Hamiltonian are:

$$
\hat{H}_{\text {exch }}=-9 \% \text { total } \hat{g} / 8_{y 1} \hat{g} \%_{\text {radical }}
$$


The Ising exchange coupling constant $\stackrel{\%}{\%}$ total represents Dy ${ }^{\mathrm{III}}$-radical exchange coupling with respect to the pseudospin $\$_{D y}^{\circ}=1 / 2$ and the spin $S_{\text {radical }}=1 / 2$ on Dy ${ }^{I I I}$ and the radical sites, respectively. The exchange coupling constant was fitted through comparison of the computed and measured magnetic susceptibility using the POLY_ANISO program. ${ }^{\mathrm{S}}$

Table S6. Exchange energies E ( $\mathrm{cm}-1)$, the energy difference between each exchange doublets $\Delta t$ $(\mathrm{cm}-1)$ and the main values of the gz for the lowest two exchange doublets of $\mathbf{1}$.

\begin{tabular}{|c|c|c|c|}
\hline & \multicolumn{3}{|c|}{1} \\
\hline & $E$ & $\Delta_{t}$ & $g_{z}$ \\
\hline \multirow{2}{*}{1} & 0.00 & & \\
\cline { 2 - 2 } & 0.70 & 0.70 & 16.665 \\
\hline \multirow{2}{*}{2} & 20.84 & & \\
\cline { 2 - 2 } & 21.49 & 0.65 & 20.464 \\
\hline
\end{tabular}

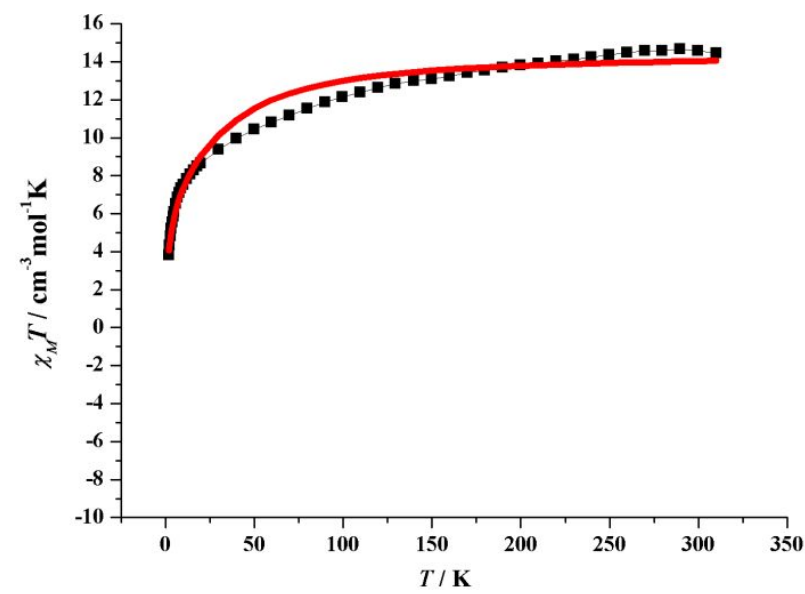

Figure S17. Calculated (red solid line) and experimental (black square dot) data of magnetic susceptibilities of complex $\mathbf{1}$. The fitted intermolecular interaction $z J^{\prime}$ of complex 1 is $-0.60 \mathrm{~cm}^{-1}$. 


\section{References}

S1. Y. Sun, N. Ross, S.-B. Zhao, K. Huszarik, W.-L. Jia, R.-Y. Wang, D. Macartney and S. Wang, J. Am. Chem. Soc., 2007, 129, 7510-7511.

S2. (a) J. D. Rinehart, M. Fang, W. J. Evans and J. R. Long, Nat. Chem., 2011, 3, 538; (b) J. D. Rinehart, M. Fang, W. J. Evans and J. R. Long, J. Am. Chem. Soc., 2011, 133, 14236-14239; (c) S. Demir, J. M. Zadrozny, M. Nippe and J. R. Long, J. Am. Chem. Soc., 2012, 134, 18546-18549; (d) C. A. Gould, L. E. Darago, M. I. Gonzalez, S. Demir and J. R. Long, Angew. Chem. Int. Ed., 2017, 56, 10103-10107.

S3. F. Aquilante, J. Autschbach, R. K. Carlson, L. F. Chibotaru, M. G. Delcey, L. De Vico, I. Fdez. Galván, N. Ferré, L. M. Frutos, L. Gagliardi, M. Garavelli, A. Giussani, C. E. Hoyer, G. Li Manni, H. Lischka, D. Ma, P. Å. Malmqvist, T. Müller, A. Nenov, M. Olivucci, T. B. Pedersen, D. Peng, F. Plasser, B. Pritchard, M. Reiher, I. Rivalta, I. Schapiro, J. Segarra-Martí, M. Stenrup, D. G. Truhlar, L. Ungur, A. Valentini, S. Vancoillie, V. Veryazov, V. P. Vysotskiy, O. Weingart, F. Zapata, R. Lindh, MOLCAS 8: New Capabilities for Multiconfigurational Quantum Chemical Calculations across the Periodic Table, J. Comput. Chem., 2016, 37, 506.

S4. (a) Chibotaru, L. F.; Ungur, L.; Soncini, A. Angew. Chem. Int. Ed., 2008, 47, 4126. (b) Ungur, L.; Van den Heuvel, W.; Chibotaru, L. F. New J. Chem., 2009, 33, 1224. (c) Chibotaru, L. F.; Ungur, L.; Aronica, C.; Elmoll, H.; Pilet, G.; Luneau, D. J. Am. Chem. Soc., 2008, 130, 12445.

S5. Lines, M. E. J. Chem. Phys. 1971, 55, 2977.

S6. (a) Mondal, K. C.; Sundt, A.; Lan, Y. H.; Kostakis, G. E.; Waldmann, O.; Ungur, L.; Chibotaru, L. F.; Anson, C. E.; Powell, A. K. Angew. Chem. Int. Ed. 2012, 51, 7550. (b) Langley, S. K.; Wielechowski, D. P.; Vieru, V.; Chilton, N. F.; Moubaraki, B.; Abrahams, B. F.; Chibotaru, L. F.; Murray, K. S. Angew. Chem. Int. Ed. 2013, 52, 12014. 